\title{
Article \\ Textured and Hierarchically Constructed Polymer Micro- and Nanoparticles
}

\author{
Klaus-Peter Kronfeld $^{1, * \mathbb{D}}$, Raminta Mazetyte-Stasinskiene ${ }^{1} \mathbb{D}$, Xuejiao Zheng ${ }^{2} \mathbb{D}$ and Johann Michael Köhler ${ }^{1} \mathbb{D}$ \\ 1 Department of Physical Chemistry and Microreaction Technology, Institute for Chemistry and Biotechnology, \\ Technical University Ilmenau, Weimarer Str. 32, 98693 Ilmenau, Germany; \\ raminta.mazetyte@tu-ilmenau.de (R.M.-S.); michael.koehler@tu-ilmenau.de (J.M.K.) \\ 2 BioNTech IMFS GmbH, 55743 Idar-Oberstein, Germany; Xuejiao.Zheng@biontech.de \\ * Correspondence: klaus-peter.kronfeld@tu-ilmenau.de
}

check for updates

Citation: Kronfeld, K.-P.;

Mazetyte-Stasinskiene, R.; Zheng, X.; Köhler, J.M. Textured and Hierarchically Constructed Polymer Micro- and Nanoparticles. Appl. Sci. 2021, 11, 10421. https://doi.org/ 10.3390/app112110421

Academic Editor: Alberto Milani

Received: 13 October 2021

Accepted: 2 November 2021

Published: 5 November 2021

Publisher's Note: MDPI stays neutral with regard to jurisdictional claims in published maps and institutional affiliations.

Copyright: (C) 2021 by the authors. Licensee MDPI, Basel, Switzerland. This article is an open access article distributed under the terms and conditions of the Creative Commons Attribution (CC BY) license (https:/ / creativecommons.org/licenses/by/ $4.0 /)$.

\begin{abstract}
Microfluidic techniques allow for the tailored construction of specific microparticles, which are becoming increasingly interesting and relevant. Here, using a microfluidic hole-plate-device and thermal-initiated free radical polymerization, submicrometer polymer particles with a highly textured surface were synthesized. Two types of monomers were applied: (1) methylmethacrylate (MMA) combined with crosslinkers and (2) divinylbenzene (DVB). Surface texture and morphology can be influenced by a series of parameters such as the monomer-crosslinker-solvent composition, surfactants, and additives. Generally, the most structured surfaces with the simultaneously most uniform particles were obtained in the DVB-toluene-nonionic-tensides system. In a second approach, poly-MMA (PMMA) particles were used to build aggregates with bigger polymer particles. For this purpose, tripropyleneglycolediacrylate (TPGDA) particles were synthesized in a microfluidic co-flow arrangement and polymerized by light- irradiation. Then, PMMA particles were assembled at their surface. In a third step, these composites were dispersed in an aqueous acrylamide-methylenebisacrylamide solution, which again was run through a co-flow-device and photopolymerized. As such, entities consisting of particles of three different size ranges-typically $0.7 / 30 / 600 \mu \mathrm{m}$-were obtained. The particles synthesized by both approaches are potentially suitable for loading with or incorporation of analytic probes or catalysts such as dyes or metals.
\end{abstract}

Keywords: microfluidic droplet generation; free radical polymerization; textured surface; particle assembling; controlled aggregation

\section{Introduction}

Interest in micro- and nanoparticles has generally been increasing, particularly in polymer particles with enhanced surface roughness and structure, to meet applicationspecific demands such as controlled drug delivery [1,2], super-hydrophobic [3] and icephobic [4,5] surfaces, attachment of cells [6], and adhesion of metal nanoparticles [7,8]. For these purposes, the particle surface can be modified by introducing wrinkles and corrugations [1,3,6,9-14] as well as controlled or self-assembly of particles [15-17] into aggregates.

In most cases, surfaces become wrinkled when two prerequisites are fulfilled: (1) a thin top layer is formed, which is mostly stiffer (higher Young's modulus) than the underlying bulk; and (2) a compressive stress builds up in this layer due to either shrinkage of the bulk or expansion of the layer. Several methods have been used to meet the prerequisites in practice such as plasma treatment [6] or chemical oxidation of the surface [9], solvent evaporation from particles [1,10,11], spray-drying [12], as well as thermal treatment using the thermal expansion mismatch of the bulk and layer [13] or polymerization shrinkage of the particle core [14]. Liu et al. [11], who synthesized wrinkled poly-divinylbenzene particles, especially motivated us to study similar systems using microfluidic techniques.

During recent years, fabricating micro- and nanoparticles has increasingly become the focus of research. The production of complex-constructed particles by a controlled 
assembly of smaller particles is being investigated for inorganic and polymer materials. These research activities are being driven by the applicability of such particles as miniaturized responsive tools, nanotransducers, and labels or carriers for drugs and other active agents, and by the basic scientific interest in understanding and designing functional and biomimetic structures at supermolecular, subcellular, and cellular scales. The assembly behavior of particles is determined by the physical properties, chemical surface affinity, particles' geometry, and entropic effects [18].

Lunn et al. presented a general rational approach for the controlled formation of particle assemblies with special geometries using colloidal building units with chemically distinct surface regions. Their site-specific surface interactions can be achieved by simple physical differences as well as by specific molecular interactions as in case of DNA hybridization, which is applicable for inorganic as well as polymer particles and leads to the production of colloidal molecules [19]. Block copolymers consisting of variable building blocks were shown to aggregate into nanostructures with locally distinguishable surface regions [20]. They form nanoparticles with partly high geometrical complexity and can be used for generating a whole spectrum of composed nanoparticles.

The formation of hierarchical nanostructures can be based on supramolecular polymer components as well. This approach was developed using triarylamines, for example [21], which supports self-assembly of macromolecular units into different complex nanoparticulate structures. Additionally, specific star-polymers with one polyionic arm can form micelles, which aggregate and eventually form superstructures up to the micrometer range mediated by counterions [22]. Alternatively, hybrid nanoparticles can be prepared by the generation of copolymer seeds on silica spheres and the subsequent growth of the seeds by crystallization-driven self-assembly (CDSA) [23].

In addition to a molecular bottom-up strategy, hierarchically structured particles can be constructed by assembling more basic particles. To this end, microfluidics are a useful tool [24]. Nanoporous particles have been produced by incorporating both polymer and $\mathrm{TiO}_{2}-$ nanoparticles inside microdroplets and subsequent solvent evaporation. The polymer components are removed upon calcination, resulting in nanoporous $\mathrm{TiO}_{2}$ [25]. In [26], composite particles of larger polystyrene and smaller silica nanoparticles were obtained as intermediates to produce Janus-like silica nanoparticles each half-coated with polystyrene and polyacrylic acid.

The combination of controlling the chemical surface state and the morphology of the forming particles with spontaneous particle assembly can lead to a large spectrum of different particle structures. In the following, we report the experimental results of the generation of highly textured and hierarchically composed polymer particles of large specific surface.

\section{Materials and Methods}

\subsection{Materials}

Unless otherwise stated, chemicals were fine grade or higher and used as received. As monomers, we used DVB for synthesis 65\% (Merck, Kenilworth, NY, USA), MMA (Merck), TPGDA 90\% (abcr, Setagaya City, Tokyo), ethyleneglycoldimethacrylate (EGDMA, Merck), and acrylic acid (Sigma-Aldrich, Saint Louis, MO, USA), acrylamide-methylenebisacrylamide 19:1 for electrophoresis (AA-MBA, Fisher Scientific, Hampton, NH, USA). The solvents included toluen (Carl Roth), methanol (Merck), ethanol 96\% (Carl Roth, Karlsruhe, Germany), and bi-distilled water. The surfactants were sodiumdodecylsulfate (SDS, Fluka, Buchs, Switzerland), cetyltrimethylammoniumbromide (CTAB, Merck), Brij52 (Sigma-Aldrich), and Span20 (Merck). The used polyelectrolytes included poly-diallyldimethylammonium chloride (PDADMAC) 35\% in water MW < 100,000 (Sigma-Aldrich), and Na-poly-styren esulfonate (PSS; MW 1,000,000; Sigma-Aldrich). The thermal radical starter was azobisisobutyronitrile (AIBN, Sigma-Aldrich)and the photoinitiators were phenylbis(2,4,6trimethylbenzoyl)phosphine oxide (Irgacure 819, Ciba, Basel, Switzerland) in 3 M solution in anisole; lithium 2,4,6-trimethylbenzoyl-phenylphosphinate (Li-TPO) was synthesized 
according to the literature [27]. As continuous flowing phases were used, for the hole-plate device, water with surfactants added, and for the co-flow device, either silicone oil $500 \mathrm{cSt}$ (Carl Roth) or a $1.5 \%$ solution of methylcellulose (3000-5600 cP viscosity of a $2 \%$ solution, ACROS) in water was used. For the polyacrylamide (PAA) solution, MW 10,000, 50\% in water was used as the rheologic component.

\subsection{Analytical Methods}

For capturing images by scanning electron microscopy (SEM), a Hitachi S-4800 was used. Prior to measurement, highly diluted suspensions of the polymer particle samples were applied on silicon chips and dried under room conditions. The prepared silicon chips were sputtered with $\mathrm{Au}-\mathrm{Pd}$ using a Balzers SCD 004. Zeta-potentials and particle sizes in the nanometer range were measured using a Malvern Nano ZS. Beforehand, the polymer samples were purged by repeated centrifugation and washing twice with ethanol and twice with water. For imaging particles in the micrometer and submillimeter range, light microscopy was used. Incident and transmitted light as well as reflected light fluorescence microscopy were performed with a Zeiss Axioplan 2 and images were captured with a Sony SLT-A37 digital camera. For incident microscopy, a Keyence VHX-5000 was also applied. Microphotographs were measured and treated with ImageJ software.

\subsection{Droplet Generation and Thermal Polymerization}

The equipment used for the generation of a monomer in water emulsion and subsequent thermal batch polymerization was previously described [28]. The monomer-solvent mixture containing AIBN initiator was pressed through a silicon hole-plate into the continuous aqueous phase flowing in a narrow slit at a right angle. Plates with varying sizes, numbers, and arrangements of holes were applied. Typically, an array of $10 \times 10$ holes of $10 \mu \mathrm{m}$ in size was used. The emulsion was piped to the sampling tube placed inside a water bath held at constant temperature for a defined time. While resting in the tube, further components were potentially added after certain intervals. After completion of the polymerization, the sample was removed and purged as described in Section 2.2.

\subsection{Droplet Generation and In Situ Photopolymerization}

The principle of the co-flow equipment has been described several times $[29,30]$ and applied for poly-TPGDA [31] as well as poly-AA [32]. Here, for the poly-TPGDA particles, a modified flow-focus setup (see Section 3.2.2) was applied in order to produce even smaller particles. We mixed $300 \mu \mathrm{L}$ of monomer with $10 \mu \mathrm{L}$ of initiator solution (3 M Irgacure 819 in anisol). The carrier phase was a $1.5 \%$ aqueous methylcellulose solution, since it is not miscible with the monomer. Fused silica capillaries of 75 and $250 \mu \mathrm{m}$ inner width were used for the inlet and outlet, respectively. For the poly-AA particles, a stock solution was created with $225 \mathrm{mg}$ of monomer and $3.8 \mathrm{mg}$ of Li-TPO initiator dissolved in $750 \mu \mathrm{L}$ water. Typically, $200 \mu \mathrm{L}$ of stock solution was mixed with $100 \mu \mathrm{L}$ of PAA solution and the particles which were separated from $1 \mathrm{~mL}$ of a poly-TPGDA particle suspension. The PAA was necessary to prevent the poly-TPGDA particles from settling during operation. The monomer solution was injected through a metal tube with a $600 \mu \mathrm{m}$ inner diameter. In all experiments, the droplets were guided by the carrier phase through a $1.5 \mathrm{~mm}$ wide transparent glass tube to the irradiation block. There, the light of a 120 watt mercury lamp (HXP $120 \mathrm{~V}$, Leistungselektronik Jena) was fed by a $5 \mathrm{~mm}$ glass fiber cable perpendicular to the flow direction. Light intensity was adjusted using the opto-mechanical dimming unit of the lamp.

\subsection{Assembly of Particles}

To assemble nanometer PMMA particles on the surface of poly-TPGDA particles, separate batches of both were synthesized. During synthesis, the former was charged positively using PDADMAC in the carrier phase and the latter was charged negatively by copolymerization with acrylic acid. The nanoPMMA batch was then added to the poly- 
TPGDA batch in one tube, vortexed for $10 \mathrm{~s}$, and incubated for $48 \mathrm{~h}$ at room temperature. Subsequently, the formed poly-TPGDA/PMMA composites were washed 5 times with water in order to remove unbound PMMA particles.

\section{Results}

\subsection{Textured Nanoparticles of Polymethylmethacrylate and Polydivinylbenzene}

In [11], wrinkled poly-DVB particles of about $2 \mu \mathrm{m}$ were synthesized in a two-step batch process; here, we tried to adopt microfluidics in order to achieve comparable results in a one-step semi-microfluidic process. We have experience in producing submicron PMMA particles with spherical [28], branched [33], and flower-like [34] shapes. The original idea about how the surface of such polymer particles becomes textured is as follows: As polymerization of DVB occurs, a three-dimensional network is gradually formed. The polymer particle gelates while there is still a considerable amount of monomer present. The rest of the monomer is removed in the following processing, resulting in shrinkage of the particle and wrinkling of its surface. This only works in a time interval when there is a certain ratio of cured polymer to the rest of the monomer. It does not work if the particle is too soft or already too stiff. Additionally, the addition of solvents such as toluene and ethanol promotes the formation of textured surfaces.

We tried to simulate these effects first with the monomer MMA as follows:

- The monomer phase consisted of 38\% MMA, $62 \%$ toluene (volume fraction), and $11.6 \mathrm{mM}$ AIBN.

- The carrier phase consisted of $33 \%$ water, $67 \%$ methanol (volume fraction), and $1.0 \mathrm{mM}$ SDS. Methanol was present because it was reported to improve the monodispersity of the resulting PMMA emulsions $[35,36]$.

- By means of the microfluidic hole-plate device (see Section 2.3 [28]), an emulsion was produced at flow rates of $240 \mu \mathrm{L} / \mathrm{min}$ (monomer) and $1500 \mu \mathrm{L} / \mathrm{min}$ (carrier) and piped into a thermostat held at $85^{\circ} \mathrm{C}$.

- After a certain incubation time, EGDMA and DVB were added. The reason why these crosslinking components were not present from the start in the monomer phase was due to the assumption that when they are added later, they can accumulate near the particle surface, facilitating wrinkle formation.

- With increasing reaction time, the mixture became increasingly turbid; after $4 \mathrm{~h}$, it was removed from the thermostat. Coarse parts were removed manually; then, the suspension was centrifuged and washed several times, first with ethanol to extract remains of monomer and solvent and finally with water to remove the ethanol.

In a series of experiments, the influences of the incubation time and the quantity of added EGDMA and DVB were investigated. Figure 1 depicts the influence of 1, 2, 3, and 5 min incubation time at a given crosslinker quantity of $680 \mathrm{ppm}$ EGDMA $+6.8 \%$ DVB (volume fraction in relation to $100 \%$ monomer phase). After 5 min delay, the particle surface was rather sparsely textured. At 1 and 3 min delay, mainly irregular aggregates formed.

The best results in terms of spherical, well-textured particles were obtained with a 2 min incubation time. With this parameter fixed, the influence of the crosslinker composition was studied by omitting components of the initial two (Figure 2). Most textured surfaces were obtained with EGDMA alone or in combination with DVB. With DVB alone, the particles were more irregular, having the biggest substructures (knots). Without any crosslinker, particles looked similar to those upon late addition (Figure 1d). Table 1 summarizes the results of Figures 1 and 2. 


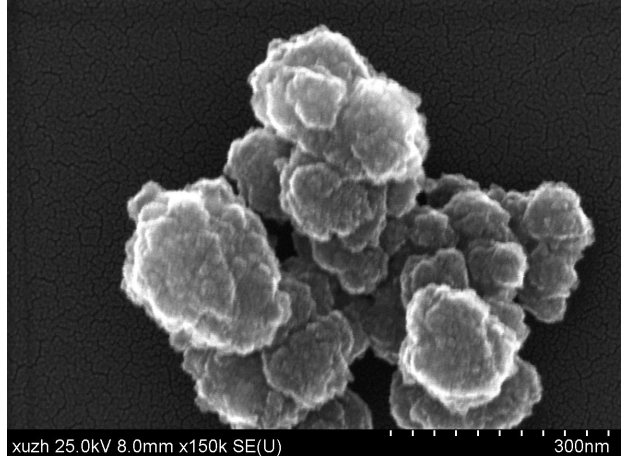

(a)

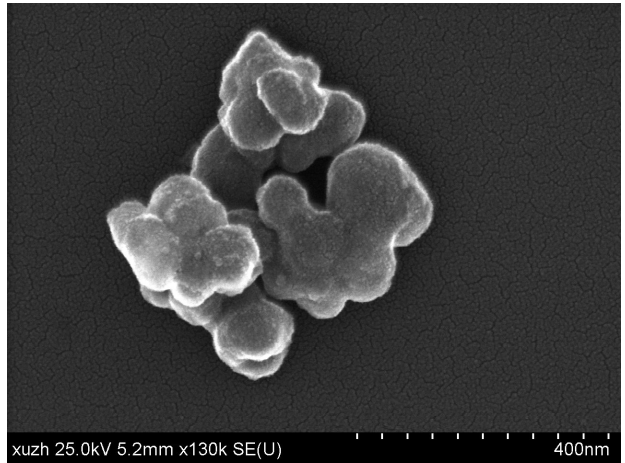

(c)

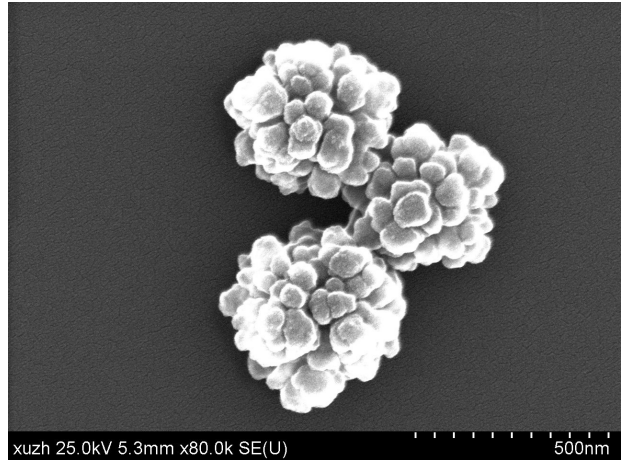

(b)

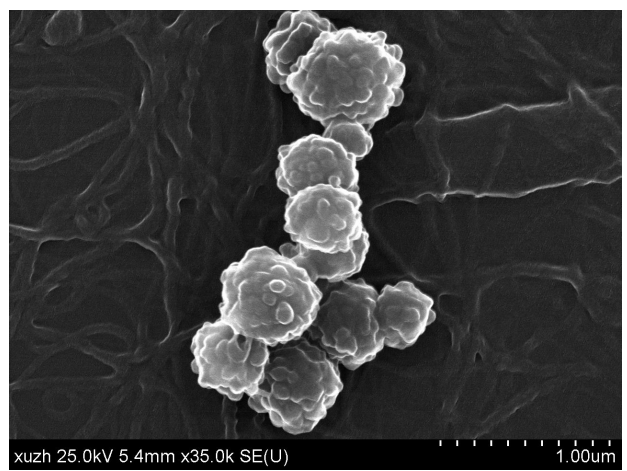

(d)

Figure 1. SEM images of PMMA particles. After distinct time intervals, 680 ppm EGDMA and 6.8\% DVB (volume fractions) were added: (a) $1 \mathrm{~min}$, (b) $2 \mathrm{~min}$, (c) $3 \mathrm{~min}$, and (d) $5 \mathrm{~min}$.

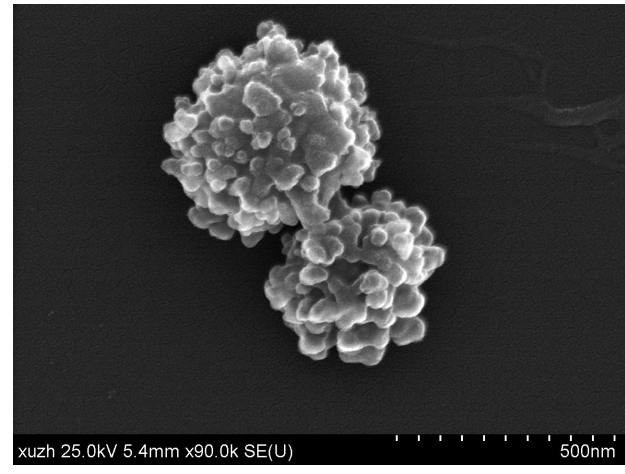

(a)

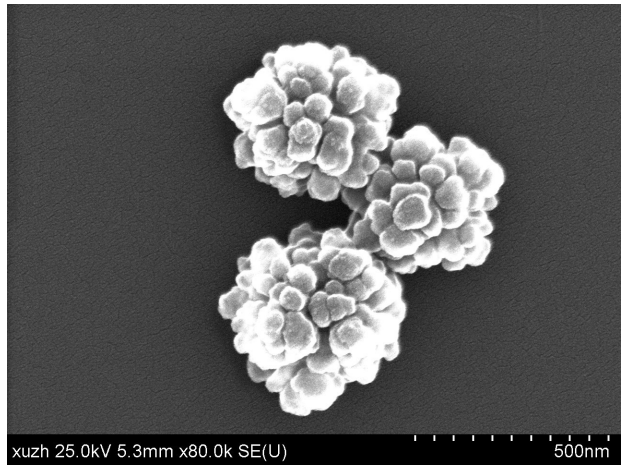

(c)

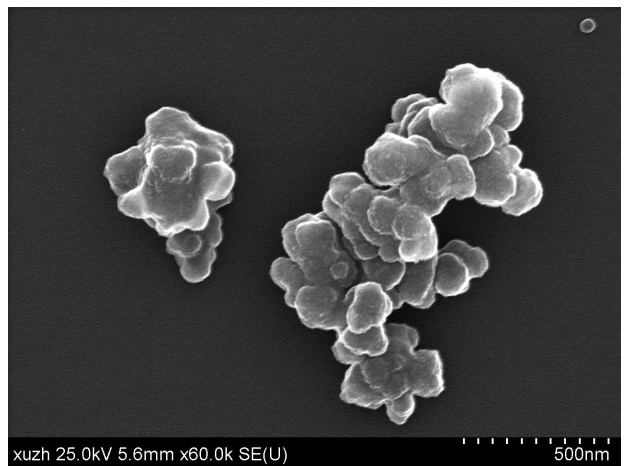

(b)

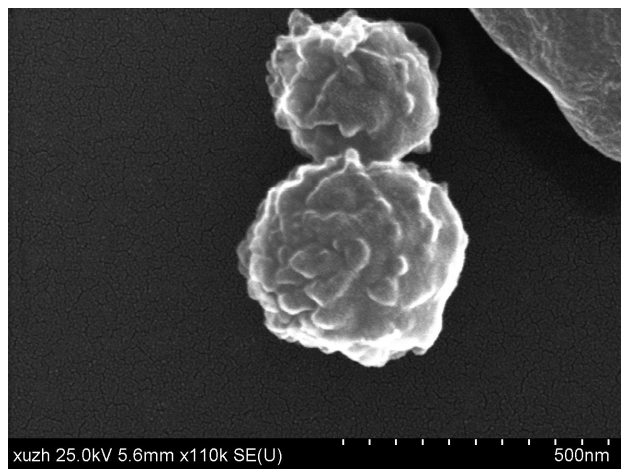

(d)

Figure 2. SEM images of PMMA particles. After $2 \mathrm{~min}$, distinct crosslinker quantities (described as volume fraction relative to the monomer phase) were added: (a) 680 ppm EGDMA, (b) $6.8 \%$ DVB, (c) 680 ppm EGDMA + 6.8\% DVB (as in Figure 1b), and (d) no crosslinker added. 
Table 1. Mean particle sizes and sizes of substructures on the particle surface derived from Figures 1 and 2.

\begin{tabular}{cccccc}
\hline Figure & $\begin{array}{c}\text { EGDMA } \\
\text { ppm }\end{array}$ & $\begin{array}{c}\text { DVB } \\
\mathbf{\%}\end{array}$ & $\begin{array}{c}\text { Incubation Time } \\
\text { min }\end{array}$ & $\begin{array}{c}\text { Particle Size } \\
\mathbf{n m}\end{array}$ & $\begin{array}{c}\text { Substructure } \\
\text { nm }\end{array}$ \\
\hline Figure 1a & 680 & 6.8 & 1 & 147 & 21 \\
Figures 1b and 2c & 680 & 6.8 & 2 & 426 & 73 \\
Figure 1c & 680 & 6.8 & 3 & 95 & n.a. \\
Figure 1d & 680 & 6.8 & 5 & 496 & 86 \\
Figure 2a & 680 & 0 & 2 & 434 & 44 \\
Figure 2b & 0 & 6.8 & 2 & n.a. & 126 \\
Figure 2d & 0 & 0 & n.a. & 354 & 44 \\
\hline
\end{tabular}

It can be seen that in the cases where distinct round particles were produced (Figures $1 \mathrm{~b}, \mathrm{~d}$ and $2 \mathrm{a}, \mathrm{d}$ ), the particles had diameters of about $350-500 \mathrm{~nm}$ with surface substructures of $40-90 \mathrm{~nm}$. The dispersity (relative standard deviation) of the diameter was $11-16 \%$ and $15-25 \%$ of the substructures.

As a second monomer, DVB was studied analogous to [11]. Unlike the monofunctional MMA monomer, DVB bears two double bonds and needs no extra crosslinking agent to form a 3D network. On the other hand, its rate of chain propagation is much slower, allowing the progress of the reaction to remain controllable.

The following protocol for the DVB monomer was applied:

- The monomer phase consisted of DVB and toluene in varying quantities, and AIBN in a concentration of $60-120 \mathrm{mM}$.

- The carrier phase consisted of water with varying types and quantities of additives (surfactants and polyelectrolytes).

- Using the microfluidic hole-plate device, an emulsion was produced at flow rates of $150-200 \mu \mathrm{L} / \mathrm{min}$ (monomer) and $1500 \mu \mathrm{L} / \mathrm{min}$ (carrier) and piped into the thermostat held at $85^{\circ} \mathrm{C}$.

- After 90 min, the reaction mixture was removed from the thermostat and treated similar to MMA.

Figure 3 depicts the effect of additives to the aqueous carrier phase on the shape of the particles. In the presence of nonionic surfactants in higher concentration, textured particles formed. With low-dosage anionic surfactant SDS as well as with cat- or anionic polyelectrolytes PDADMAC and PSS, the resulting particles were almost spherical.

In the case of PSS, the surface was nearly smooth within the image resolution; with SDS, a slightly grained texture occurred, and with PDADMAC, the surface showed faint blisters. Thus, Span20 was chosen for the following experiments to study the effect of toluene solvent on the particle structure. Figure 4 shows SEM images of particles produced with different volume fractions of monomer and solvent.

Table 2 lists the structural parameters of Figures $3 \mathrm{a}, \mathrm{b}$ and 4 .

The large particles in Figure 4a formed a super structure of about $490 \mathrm{~nm}$ diameter, which at a closer sight was composed of smaller particles, which were of comparable size to those from the other variants of 100-200 nm. Again, these smaller particles all had substructures $10-30 \mathrm{~nm}$ in size. The dispersity of the diameter in most cases was $12-17 \%$ and $15-30 \%$ of the substructures. Eventually, no strong solvent effect was detectable. 


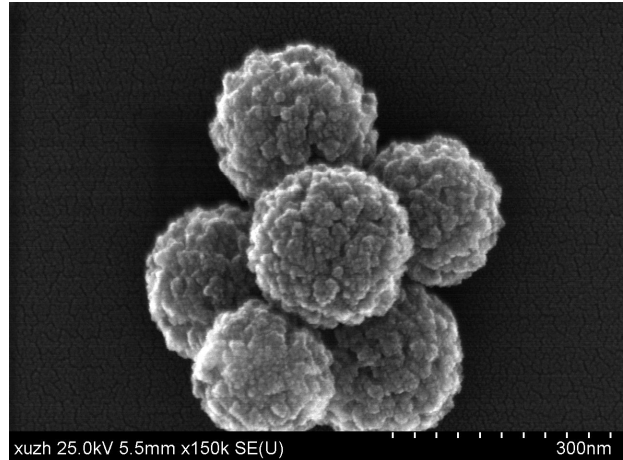

(a)

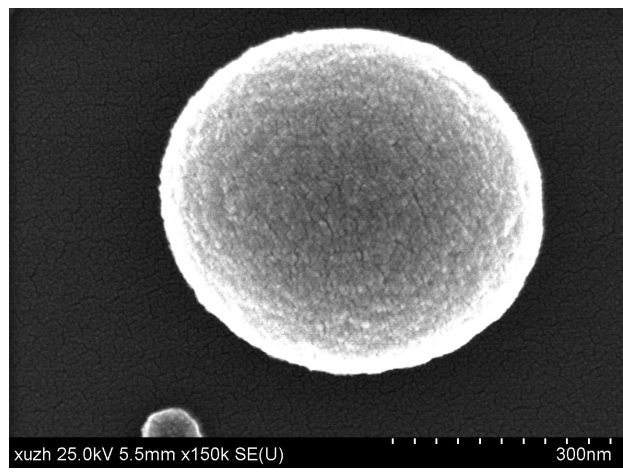

(c)

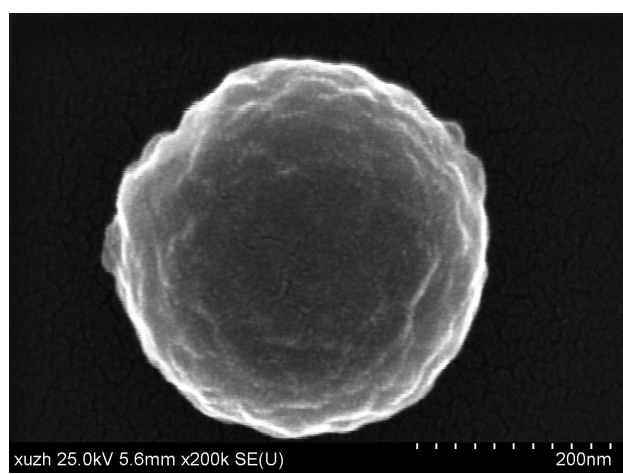

(e)

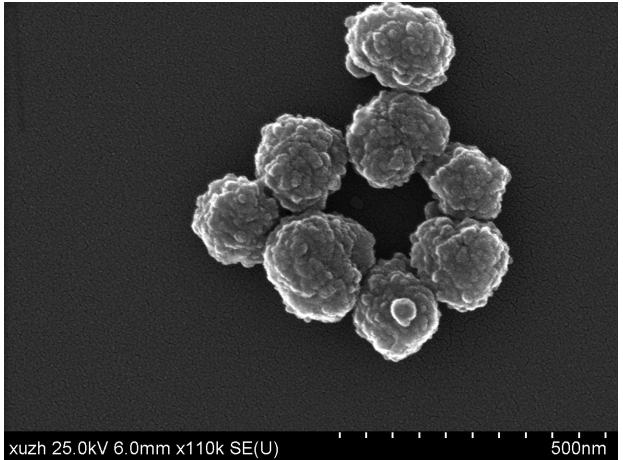

(b)

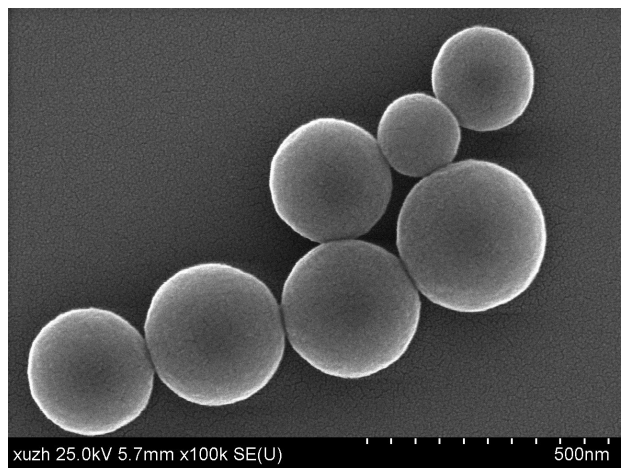

(d)

Figure 3. SEM images of poly-DVB particles synthesized in the presence of additives in the carrier phase: (a) $81.5 \mathrm{mM}$ Brij52, (b) $86.6 \mathrm{mM}$ Span20, (c) $1.5 \mathrm{mM}$ SDS, (d) $1.0 \mathrm{mM}$ PSS, and (e) $0.5 \mathrm{mM}$ (per monomer unit) PDADMAC. Monomer phase: 33\% DVB, 67\% toluene, and $66 \mathrm{mM}$ AIBN.

Table 2. Mean particle sizes and sizes of substructures on the particle surface derived from Figures 3 and 4 .

\begin{tabular}{ccccc}
\hline \multirow{2}{*}{ Figure } & Surfactant & $\begin{array}{c}\text { Toluene } \\
\text { Volume Fraction }\end{array}$ & $\begin{array}{c}\text { Particle Size } \\
\text { nm }\end{array}$ & $\begin{array}{c}\text { Substructure } \\
\text { nm }\end{array}$ \\
\hline Figure 3a & Brij52, 81.5 mM & $67 \%$ & 214 & 14 \\
Figure 3b & Span20, 86.6 mM & $67 \%$ & 172 & 20 \\
\hline Figure 4a & Span 20, 173.3 mM & $67 \%$ & 121 & 26 \\
Figure 4b & Span 20,173.3 mM & $50 \%$ & 182 & 18 \\
Figure 4c & Span 20,173.3 mM & $33 \%$ & 185 & 26 \\
Figure 4d & Span 20,173.3 mM & $25 \%$ & 100 & 11 \\
Figure 4e & Span 20,173.3 mM & $0 \%$ & 164 & 19 \\
\hline
\end{tabular}




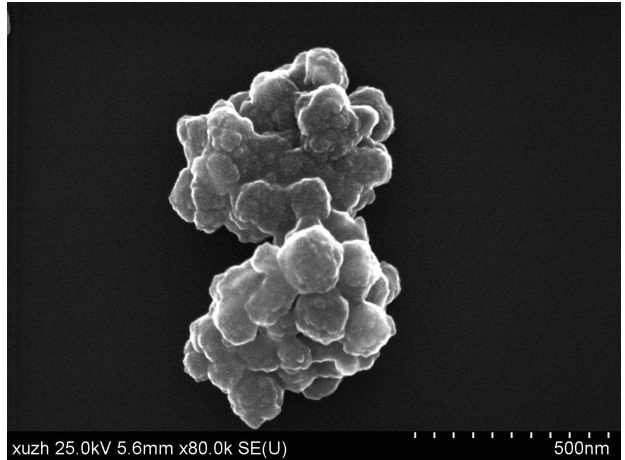

(a)

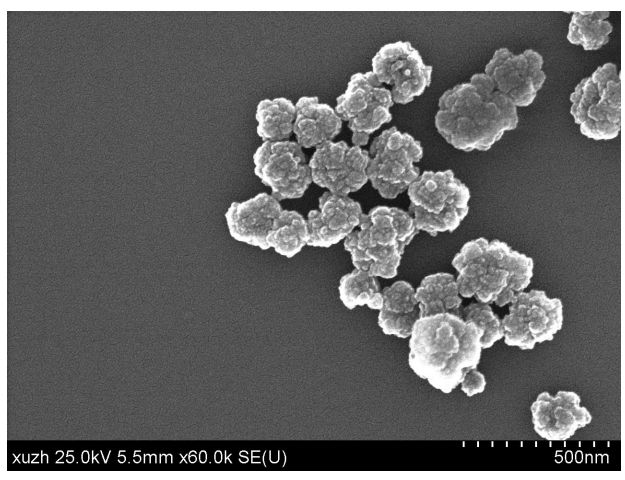

(c)

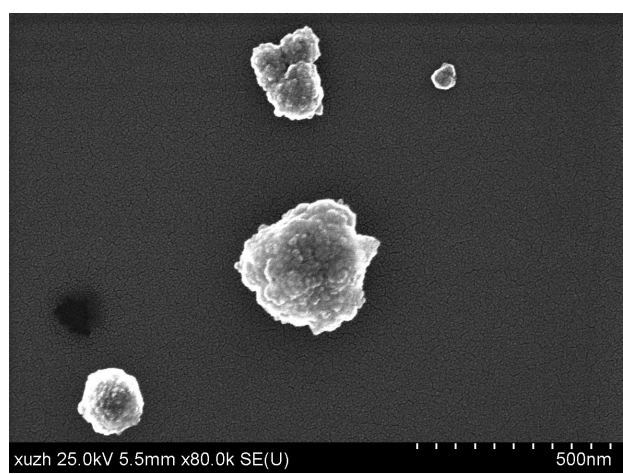

(e)

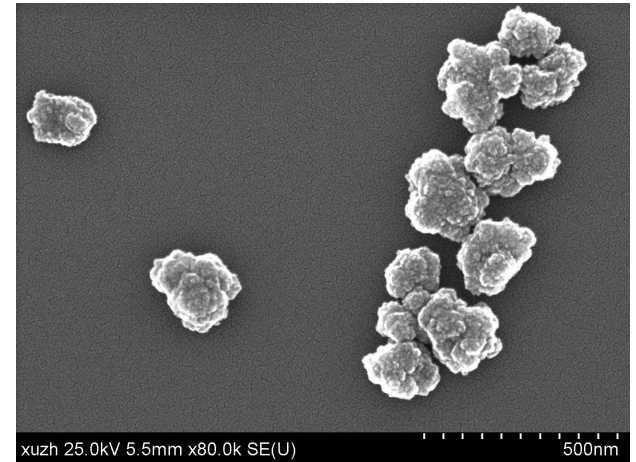

(b)

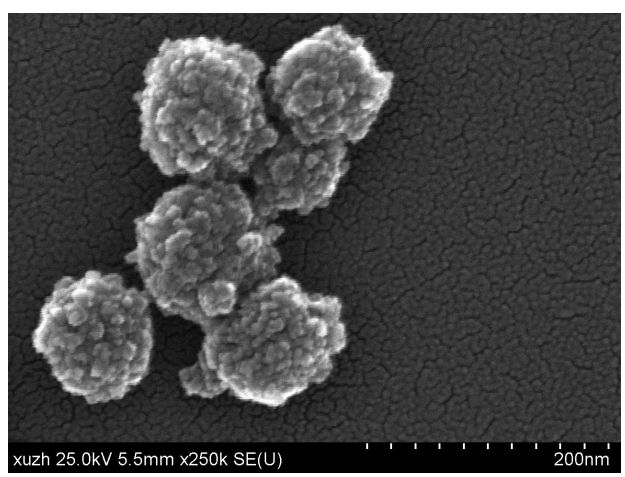

(d)

Figure 4. SEM images of poly-DVB particles synthesized with varying toluene contents (volume fractions): (a) 67\%, (b) 50\%, (c) 33\%, (d) 25\%, and (e) $0 \%$; $172.3 \mathrm{mM}$ Span20 in all cases.

\subsection{Hierarchically Constructed Particles of Poly-Acrylamid/TPGDA/MMA}

Highly structured particles and surfaces can also be obtained by multistep processes in which presynthesized particles of different sizes and natures are combined into aggregates. As such, we successfully produced poly-MMA on- poly-TPGDA in poly-Acrylamide particles. Poly-MMA and poly-TPGDA particles were synthesized independently, the former on the nanometer scale with positive electrical surface charge and the latter negatively charged and larger. The smaller particles were then assembled to the surface of the larger ones owing to electrostatic attraction, and the resulting composites were separated. In a final step, the composites were incorporated in even larger acrylamide monomer droplets, which were photo-cured to produce hydrogel particles. 


\subsubsection{Synthesis of PMMA Nanoparticles}

Surface charged polymer nanoparticles were synthesized similar to the description in Section 3.1 using hydrophilic polycationic polymer PDADMAC in the aqueous carrier phase and hydrophobic monomer MMA in the monomer phase according to [7]. PDADMAC acts as an interface stabilizing agent for emulsification of the dispersed phase in order to control particles size and surface charge.

- The monomer phase consisted of 97\% MMA, 3\% EGDMA (volume fractions), and $30 \mathrm{mM}$ AIBN. When indicated, Nile red was introduced to enable detection by fluorescence microscopy.

- The carrier phase consisted of water with variable amounts of poly-DADMAC.

- By means of the microfluidic hole-plate device, an emulsion was produced at variable flow rates and piped into the thermostat held at $97^{\circ} \mathrm{C}$.

- After $60 \mathrm{~min}$, the reaction mixture was removed from the thermostat and treated as described.

Polymer particles with a mean size of about $800 \mathrm{~nm}$ were obtained at a $3.23 \mathrm{~g} / \mathrm{L}$ PDADMAC (20 mM per monomer unit) concentration and 1200/70 $\mu \mathrm{L} / \mathrm{min}$ flow rate ratio of carrier to monomer. By changing the flow rate ratio or PDADMAC concentration, it was possible to tune the mean size of the nanoparticles from 800 to $100 \mathrm{~nm}$ (Figure 5). By reducing the monomer phase flow rate (carrier flow constant at $1200 \mu \mathrm{L} / \mathrm{min}$ ), the particle size decreased, but their polydispersity increased from $8-15 \%$. The particle surface charge was positive (zeta potential $+35 \mathrm{mV}$ ) because of the positively charged surface layer of PDADMAC on the PMMA cores. At a higher PDADMAC concentration of $6.47 \mathrm{~g} / \mathrm{L}$ (40 $\mathrm{mM}$ per monomer unit), the zeta potential increased to $+50 \mathrm{mV}$.

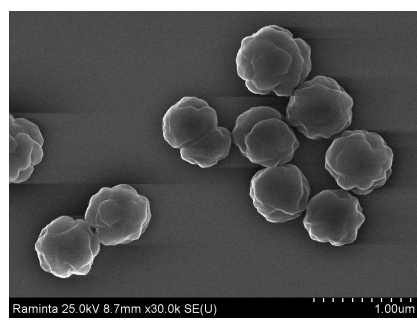

(a)

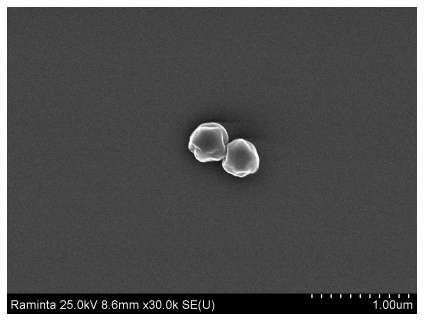

(d)

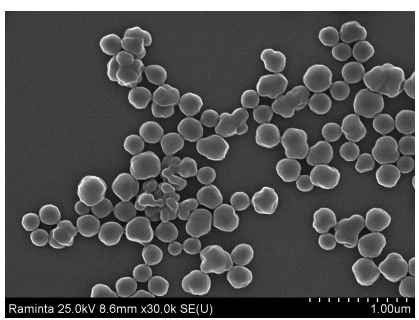

(b)

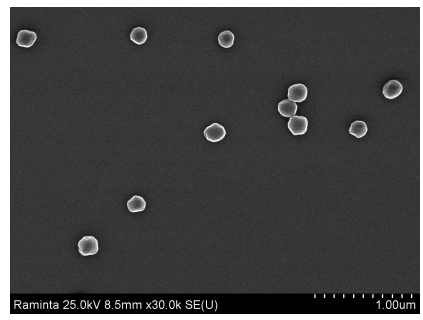

(e)

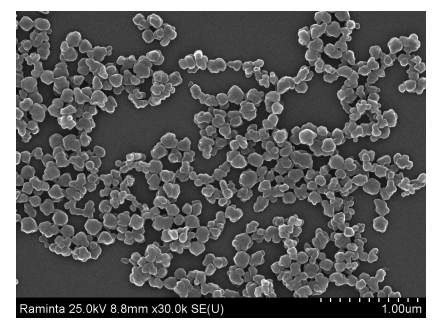

(c)

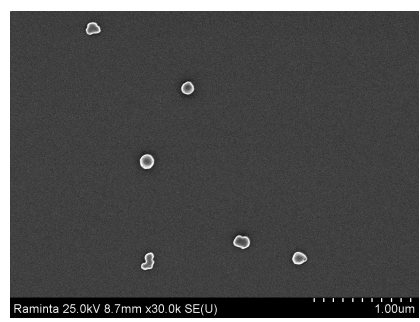

(f)

Figure 5. SEM pictures of PDADMAC-surface-modified PMMA nanoparticles produced with varying carrier/monomer flow rate ratios: (a) $1200 / 60 \mu \mathrm{L} / \mathrm{min}$, (b) $1200 / 30 \mu \mathrm{L} / \mathrm{min}$, (c) $1200 / 15 \mu \mathrm{L} / \mathrm{min}$, (d) $2000 / 60 \mu \mathrm{L} / \mathrm{min}$, (e) $2000 / 30 \mu \mathrm{L} / \mathrm{min}$, and (f) $2000 / 15 \mu \mathrm{L} / \mathrm{min}$.

\subsubsection{Synthesis of Poly-TPGDA Microparticles}

Poly-TPGDA particles were prepared in a co-flow capillary-based microfluidic device (Figure 6) at ambient temperature. The monomer droplets formed were cured on the flow in the adjacent irradiation unit by photopolymerization. Again, fluorescence dyes can be added to the monomer, if labeling of the particles is desired.

Particle size was tuned from 460 to $10 \mu \mathrm{m}$ by increasing the carrier/monomer flow rate ratio from 50 to $700 \mu \mathrm{L} / \mathrm{min}$ (carrier: $50-700 \mu \mathrm{L} / \mathrm{min}$; monomer: constant at $1 \mu \mathrm{L} / \mathrm{min}$ ), showing an almost perfect semilogarithmic dependence (Figure 7). In case of low carrier 
flow rates, monomer droplets formed in the dripping regime with weak shear force; therefore, droplet diameters were significantly large. By increasing the carrier flow rate, the monomer thread was more focused in the secondary capillary. At flow rates above $400 \mu \mathrm{L} / \mathrm{min}$, monomer droplets formed in jetting mode due to the Plateau-Rayleigh hydrodynamic instability [37]. By adjusting the distance between the two capillaries, it was possible to create a stable jetting stream and produce particles with low polydispersity. Particle sizes used for the following assembly experiments had dispersities of ca. 15\%.

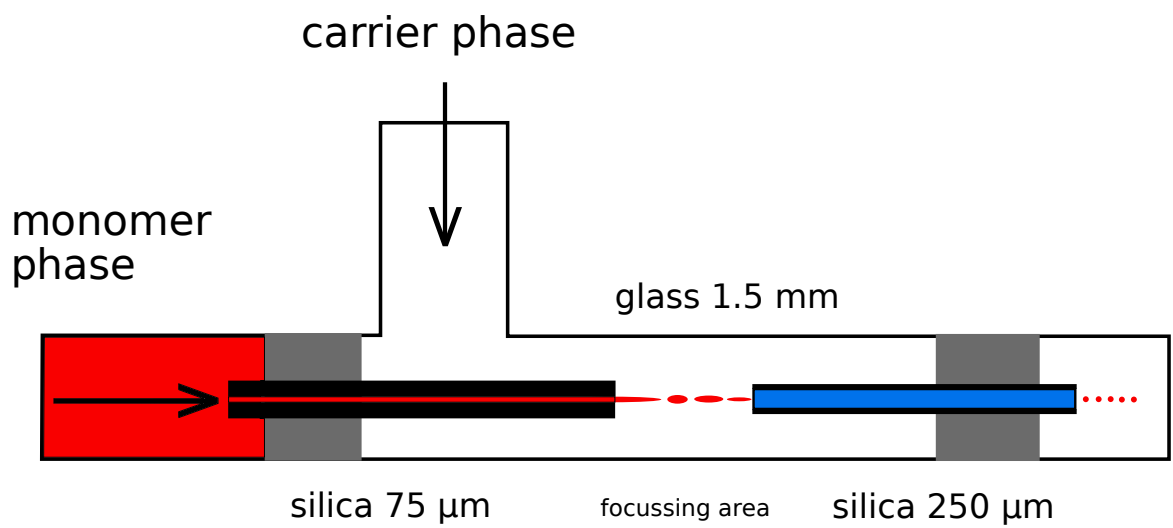

Figure 6. Scheme of the flow-focusing setup for microfluidic generation of TPGDA particles.

Additionally, the viscosity of the carrier phase can influence particle size. For a higher methyl cellulose concentration in the carrier phase, particles became smaller under the same flow conditions.

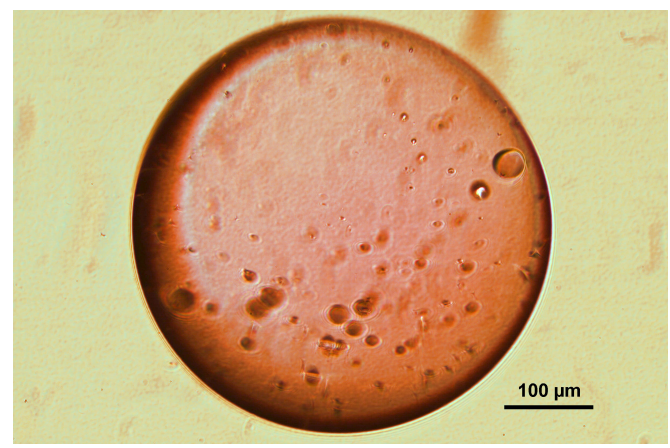

(a)

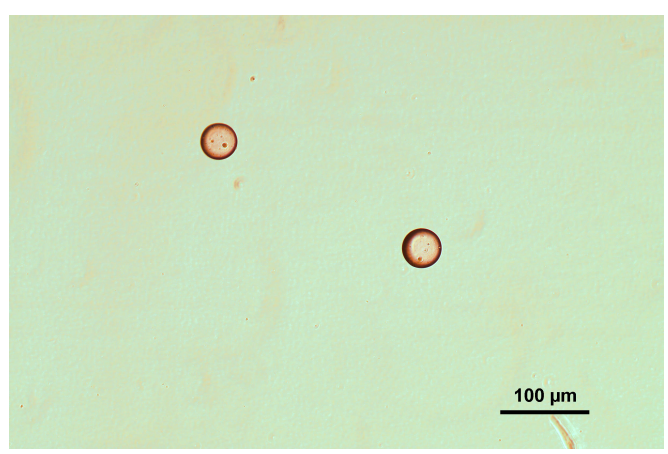

(c)

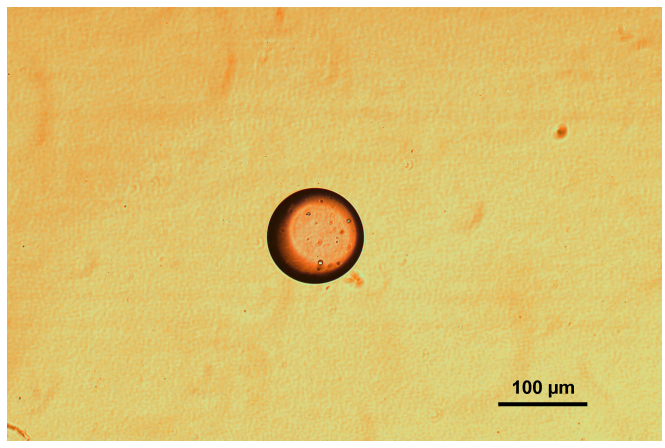

(b)

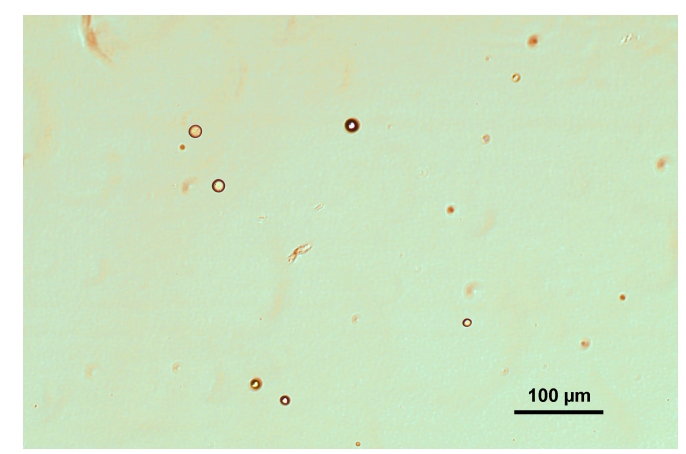

(d)

Figure 7. Cont. 


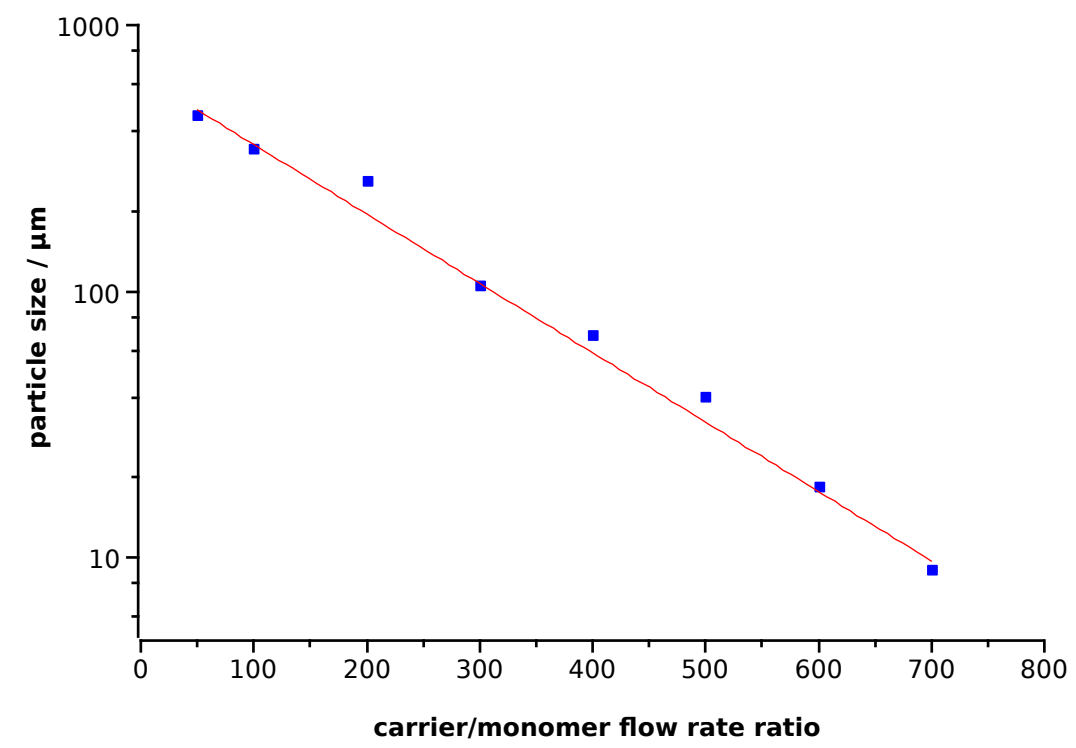

(e)

Figure 7. Optical microscope images of different poly-TPGDA particles produced with different carrier/monomer phase flow rate ratios: (a) $50 / 1 \mu \mathrm{L} / \mathrm{min}$, (b) $300 / 1 \mu \mathrm{L} / \mathrm{min}$, (c) $500 / 1 \mu \mathrm{L} / \mathrm{min}$, and (d) $700 / 1 \mu \mathrm{L} / \mathrm{min}$; (e) graph of particle size vs. carrier/monomer phase flow rate ratio.

\subsubsection{Assembling of PMMA on Poly-TPGDA Particles}

Polymer-polymer electrostatic assembly was performed in batch reaction. Composite particles were formed by mixing two types of oppositely charged nano- and microparticles. Positively charged PMMA particles (700 nm size) were added into the tube with wellwashed and negatively charged poly-TPGDA microparticles $(30-50 \mu \mathrm{m})$. Particles were vortexed for $10 \mathrm{~s}$ and incubated at room temperature. Unbound PMMA nanoparticles were removed by washing with deionized water several times. Figure 8 presents examples of PMMA on poly-TPGDA composites.

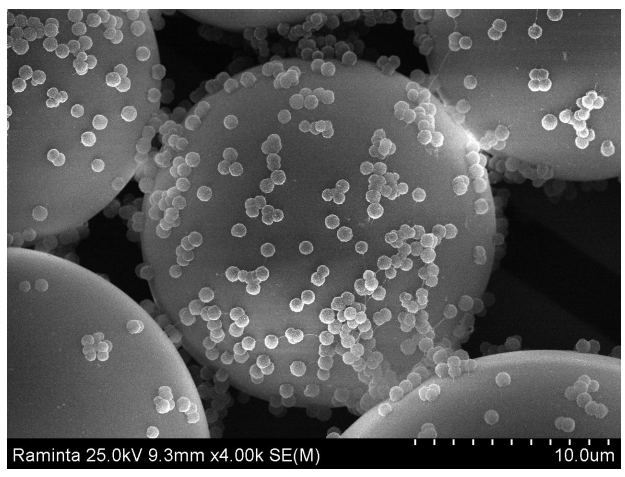

(a)

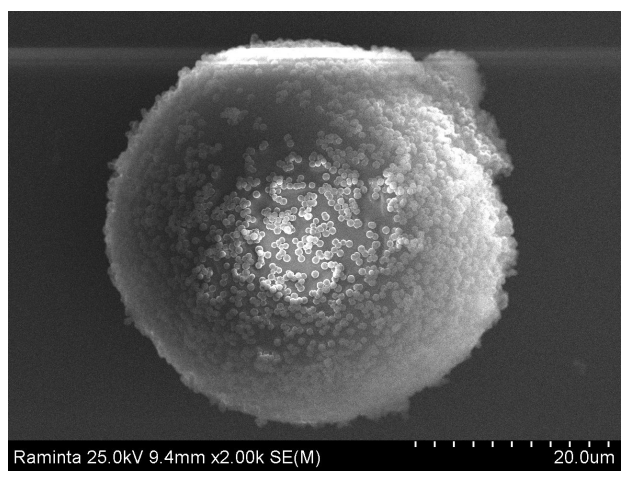

(b)

Figure 8. SEM pictures of poly-TPGDA/PMMA assembly produced with different acrylic acid concentrations in monomer phase: (a) 10\% and (b) 20\%.

Polymer-Polymer Particle Bounding Efficiency Depends on Several Factors

- First, particle surfaces need to be highly charged in order to form strong electrostatic interactions. Therefore, it is important to functionalize both particle types. PMMA particles carrying the PDADMAC layer had a zeta potential of $+35 \mathrm{mV}$. Poly-TPGDA particles were functionalized by copolymerization with acrylic acid, thus introducing a negative charge. The optimal concentration of acrylic acid in monomer phase was $10 \%$. At lower contents, particle-binding was poor, whereas with 20\%, the poly-TPGDA particles were more polydisperse. 
- Other important factors are the concentration of smaller bound particles and incubation time. In order to allow both types of particles to closely contact, all assembling experiments were performed with a large excess of PMMA particles, and the mixture was incubated for $48 \mathrm{~h}$. After this period, even the smaller particles had settled and bound to the surface of the lager ones (Figure 9).

These produced composite particles suspended in water were quite stable: they remained unchanged after several months of storage and upon mechanical agitation.

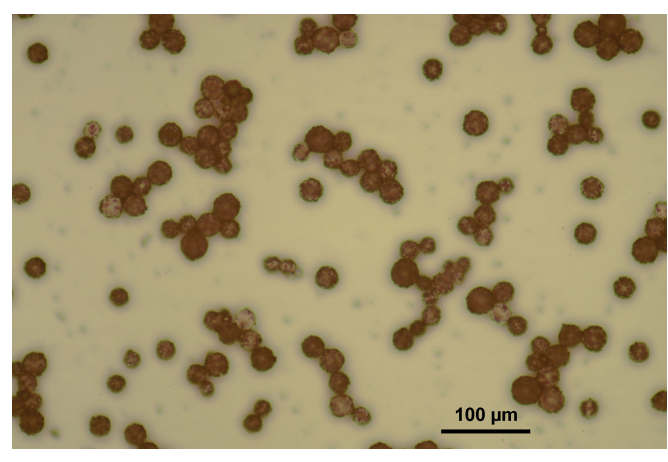

(a)

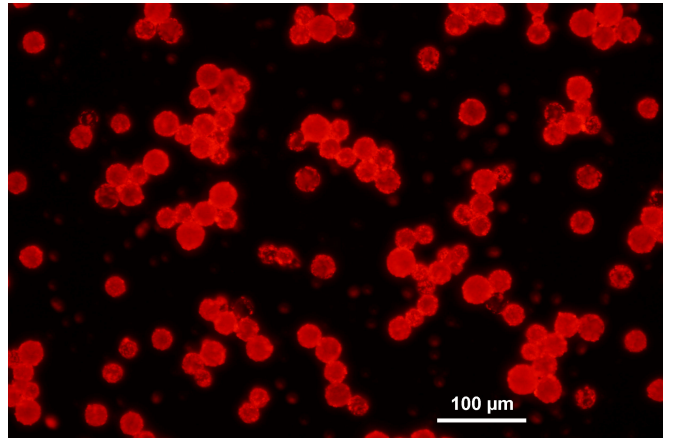

(b)

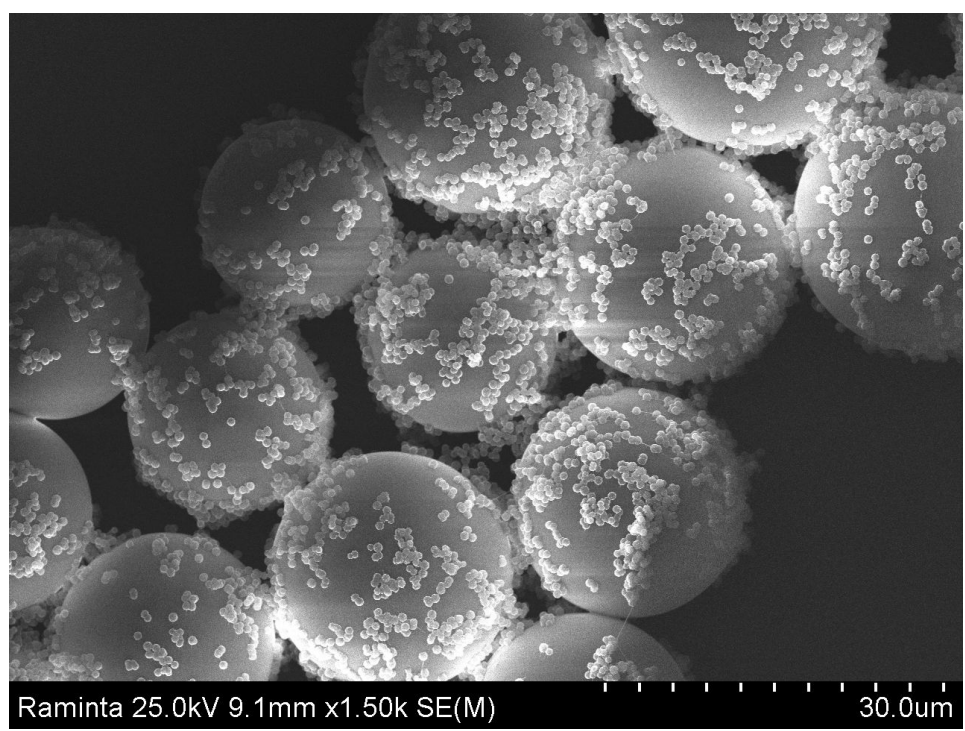

(c)

Figure 9. Formed poly-TPGDA/PMMA composites after $48 \mathrm{~h}$ incubation at room temperature: (a) bright field image, (b) fluorescence image, and (c) SEM image.

\subsubsection{Synthesis of PAA Particles Containing Poly-MMA on Poly-TPGDA Particles}

Unlike the above discussed monomers, acrylamide is not polymerized in bulk but dissolved in water, yielding hydrogel particles when a crosslinker (methylenebisacrylamide) is present. These particles can also be size-tuned by changing the monomer/carrier phase flow rate ratio. In order to suspend poly-(MMA/TPGDA) composites in acrylamide monomer solution, rheologic additives are necessary to prevent the composites from early settling. For this purpose, variable quantities of $50 \%$ polyacrylamide solution were added to the monomer phase. Figure 10 shows the dependence of the particle size on the flow rate ratio (monomer rate constant at $30 \mu \mathrm{L} / \mathrm{min}$ ) for different portions of PAA solution. At $300 \mu \mathrm{L} /$ min carrier flow, particles 1050-950 $\mu \mathrm{m}$ in size were produced (dispersity $7.5 \%$ ). By increasing the flow rate to $1200 \mu \mathrm{L} / \mathrm{min}$, particle sized reduced to around $500 \mu \mathrm{m}$. 


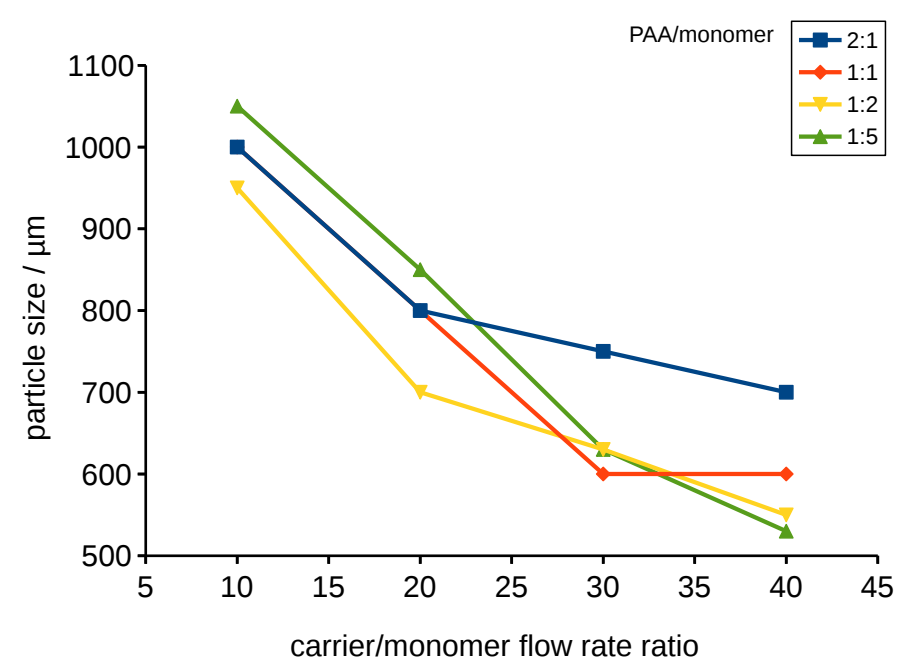

Figure 10. Graph of average PAA particle size vs. carrier/monomer flow rate ratio (monomer flow rate of $30 \mu \mathrm{L} / \mathrm{min}$ ) with different portions of rheologic additive PAA. Parameters: ratio of PAA (50\% in water, MW 10,000) to AA monomer stock solution.

Figure 11 demonstrates the effect of the depletion of poly-(MMA/TPGDA) composites from the final PAA particles when the thickener present was insufficient. When acrylamide monomer with dispersed composites but without thickener was transferred into a $1 \mathrm{~mL}$ syringe, all composites settled down inside the syringe within a few minutes. Thus, the resulting PAA particles had no composites in their volume. When PAA solution was present, the composites did not settle down completely until the end of the synthesis. The optimal condition for evenly distributed composites inside the PAA particle volume is a PAA solution to monomer phase ratio of 1:1.

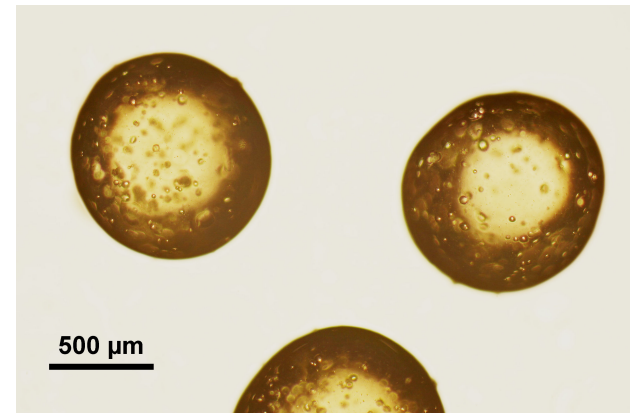

(a)

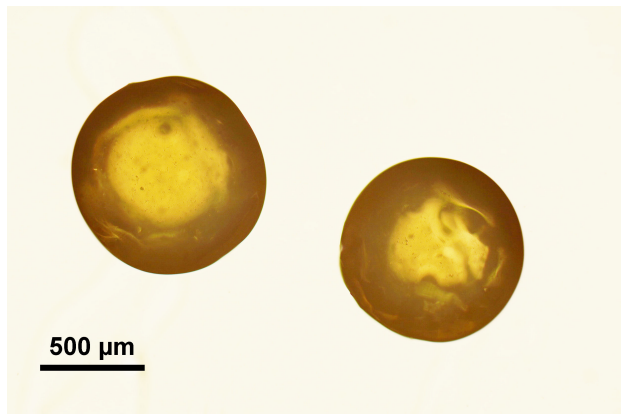

(c)

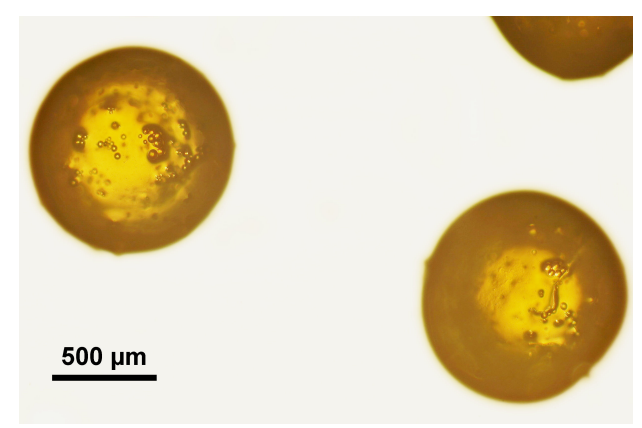

(b)

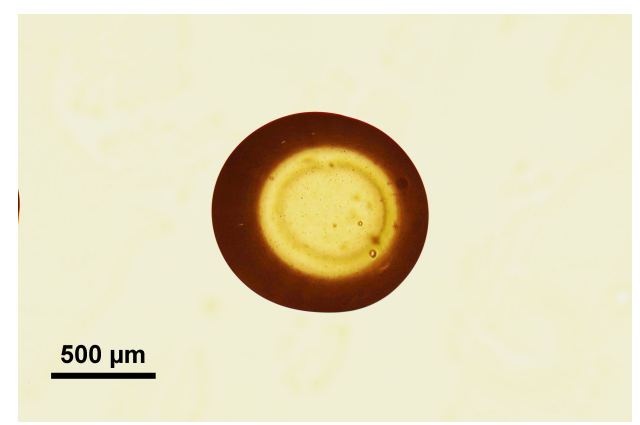

(d)

Figure 11. Effect of the depletion of poly-(MMA/TPGDA) particles (seen as small speckles) at different monomer phase compositions, i.e., the ratio of thickener to monomer stock solution: (a) 2:1, (b) 1:1, (c) 1:2, and (d) 1:5; the flow rate carrier/monomer was always $300 / 30 \mu \mathrm{L} / \mathrm{min}$. 


\section{Discussion}

\subsection{Textured Nanoparticles}

The experiments showed that with MMA as well as DVB particles, textured surfaces can be produced.

In the case of MMA, the particle diameter was about $400 \mathrm{~nm}$, having surface substructures of about $60 \mathrm{~nm}$. We previously reported flower-like PMMA particles of similar shape but larger size: particles about double the size and substructures about the four-fold size [34]. Those particles were obtained from a monomer phase that was 99\% MMA + 1\% EGDMA + $21.3 \mathrm{mM}$ AIBN and the carrier phase was water with $0.11-0.56 \mathrm{~g} / \mathrm{L}$ (1-5 mM per monomer unit) poly-N-vinylpyrrolidone (PVP) using the same equipment at $97^{\circ} \mathrm{C}$. The explanation is that smaller particles formed at earlier stages of the polymerization and grew and aggregated to larger ones, which was stimulated by PVP. However, the presence of extra surfactant, SDS, or CTAB in relevant concentrations prevented aggregation, yielding only spherical shapes. This is in contrast to the actual observation, where textured particles were found in the absence of PVP but with considerable amounts of SDS. The main differences between the experiments are:

- The dilution effect of the monomer due to the high toluene content;

- Lower temperature and AIBN concentration;

- The presence of methanol in the carrier phase.

The last factor is assumed to be of minor importance since it generates perfectly round particles $[35,36]$. Nevertheless, it can play a role because methanol facilitates the passage of MMA into the aqueous phase. We assumed that due to factors 1 and 2, the polymerization rate was considerably lower, providing the particles more time and a higher probability to aggregate despite the electrically repulsive effect between them caused by SDS. Aggregation was further enhanced since the extra solvent toluene prolongs the time of the sticky gel phase until solidification.

In the case of DVB, typical particles were about $150 \mathrm{~nm}$ in size, having $20 \mathrm{~nm}$ wide substructures. Here, the above-reported effects for MMA were observed (see Figure 3) when ionic detergents or polyelectrolytes were present. This is in line with the above assumption of polymerization rate and gel time because of the higher initiator concentration used and the faster solidification due to two double bonds per molecule instead of one. The use of nonionic surfactants was therefore essential for highly textured particles. Compared to ionic surfactants such as SDS or CTAB those substances are usually applied in higher dosages, although their critical micelle concentrations are very low (Brij52: $0.067 \mu \mathrm{M}$ [38], Span20: $23 \mu \mathrm{M}$ [39]). This may explain the small size of the observed substructures. In summary, we state that our particles are textured but not wrinkled and one order of magnitude smaller than those of Liu et al. [11]. They agree fairly with our earlier model of flower-like particles [34].

The proposed mechanism is as follows: In the droplet generation unit (hole-plate device), the velocities of both the carrier and monomer phase are high (about 250 and $500 \mathrm{~mm} / \mathrm{s}$, respectively) compared to the hole dimensions $(10 \mu \mathrm{m})$. Thus, the jetting monomer phase is rapidly dispersed into very small droplets. The droplet size is modulated by the surfactant, which decreases the surface tension between the phases. Especially with nonionic tensides, the size is further reduced due to micelle formation. These droplets may also shrink due to a certain solubility of the monomer phase in the excess carrier phase but stay fluid until they enter the heating unit. When polymerization starts inside the droplets, they become increasingly gel-like, which is accelerated by the addition of crosslinkers. During this sticky gel interval, particles come into contact due to Brownian motion and van der Waals attraction, forming larger aggregates. The aggregation number is expected to be dependent on:

- Temperature: When temperature increases, the gel interval decreases but the Brownian motion increases.

- Gel interval is affected by monomer/crosslinker type and concentration, initiator type and concentration, and temperature. 
- Initial size (substructure size) is affected by surfactant type and concentration, mixing conditions, and dwell time. Smaller particles move faster and collide more often.

- Effects that stabilize or destabilize the colloidal solution include electric surface potential, electrolyte concentration, and steric stabilization.

The action of these factors is complex and sometimes contradictory. The aggregated particles are then cured until the end of the polymerization process and isolated.

\subsection{Hierarchically Constructed Particles}

The design principle of the hierarchically structured three-level system by in situ photopolymerization of acrylamide monomer solution with dispersed poly-(MMA/TPGDA) composites in it was successfully demonstrated.

Compared to Section 4.1, the obtained PMMA nanoparticles were roughly roundshaped with indications of surface substructures (Figure 5). This lower degree of texture can be attributed to the different synthesis conditions (higher temperature: $97^{\circ} \mathrm{C}$ vs. $85^{\circ} \mathrm{C}$, monomer content $97 \%+3 \%$ (MMA + EGDMA) vs. $38 \%$, and initiator concentration $30 \mathrm{mM}$ vs. $11.6 \mathrm{mM}$, and the presence of polyelectrolytes) and agrees with the model discussed above. For the approach of hierarchical assembly, the exact shape of these PMMA particles is of minor importance. However, it is crucial to create forces between these nanosized particles and the next higher size range. Surface functionalization with coupled molecular ligands or surfactants gives the ability to create specific characteristics: hydrophobic or hydrophilic properties as well as positive or negative charge. We achieved this by electrostatic interactions. Other methods might use covalent or hydrogen bonds. Unfortunately, we cannot directly quantify the surface charge of the poly-TPGDA particles because they are too large for zeta-potential measurements. Hence, it is difficult to compare them with PMMA nanoparticles in terms of surface potential. However, electrostatic assembly of particles of such different sizes was reported to be successful $[15,16]$. Tan et al. [15] used silica-micro- and alumina-nanoparticle multilayers coated with polyelectrolytes as starting materials, whereas in [16], submicron silica particles were grafted with polyacrylic acid and poly(2-dimethylamino)ethyl methacrylate, separately, and subsequently assembled. Here, we showed that the combination of polyelectrolyte-coated PMMA nanoparticles and chemically modified poly-TPGDA microparticles is also a successful approach.

Packaging micrometer composite particles in even larger hydrogel particles has some additional benefits:

- Particles can be stored, portioned, weighed, and handled more easily.

- These aggregates can be dried and re-wet without damaging the composites inside.

- The hydrogel structure allows for the diffusion of molecules in- and outside and thereby mechanically shields the composites.

These properties are especially important if the core particles are further modified for catalytic or sensor purposes. The polyacrylamide-methylenebisacrylamide copolymer conforms to this, being used as a standard hydrogel in life sciences. Because of the high polymerization rate, acrylamide is particularly suitable for in situ photopolymerization. The problem of sedimentation of the precursor particles in monomer solution was mitigated, though not resolved completely, by adding rheologic modifiers. Such components remain unchanged in the hydrogel matrix and may deteriorate its physical and chemical properties. A more elaborate method would involve integrating them chemically into the polymer matrix or using more viscous pre-polymers.

Author Contributions: Conceptualization, J.M.K. and K.-P.K.; methodology, R.M.-S., X.Z., and J.M.K.; software, X.Z.; validation, J.M.K. and K.-P.K.; formal analysis, J.M.K.; investigation, R.M.-S. and X.Z.; resources, J.M.K.; data curation, R.M.-S., X.Z., and K.-P.K.; writing-original draft preparation, K.-P.K. and R.M.-S.; writing-review and editing, K.-P.K. and J.M.K.; visualization, R.M.-S.; supervision, J.M.K.; project administration, J.M.K.; funding acquisition, J.M.K. All authors have read and agreed to the published version of the manuscript.

Funding: The work is partially supported by DFG (Ko1403/39-3). 
Institutional Review Board Statement: Not applicable.

Informed Consent Statement: Not applicable.

Data Availability Statement: The data presented in this study are available on request from the corresponding author.

Acknowledgments: We thank Deutsche Forschungsgemeinschaft for financial support in favor of project Ko1403/39-3.

Conflicts of Interest: The authors declare no conflict of interest.

\section{References}

1. Hussain, M.; Xie, J.; Hou, Z.; Shezad, K.; Xu, J.; Wang, K.; Gao, Y.; Shen, L.; Zhu, J. Regulation of Drug Release by Tuning Surface Textures of Biodegradable Polymer Microparticles. ACS Appl. Mater. Interfaces 2017, 9, 14391-14400, doi:10.1021/acsami.7b02002. [CrossRef] [PubMed]

2. Dobhal, A.; Kulkarni, A.; Dandekar, P.; Jain, R. A microreactor-based continuous process for controlled synthesis of polymethyl-methacrylate- methacrylic acid (PMMA) nanoparticles. J. Mater. Chem. B 2017, 5, 3404-3417, doi:10.1039/c7tb00560a. [CrossRef]

3. Chen, M.; Hu, W.; Liang, X.; Zou, C.; Li, F.; Zhang, L.; Chen, F.; Yang, H. A Facile All-Solution-Processed Surface with High Water Contact Angle and High Water Adhesive Force. ACS Appl. Mater. Interfaces 2017, 9, 23246-23254, doi:10.1021/acsami.7b07429. [CrossRef] [PubMed]

4. Xie, H.; Xu, W.; Fang, C.; Wu, T. Efficient and economical approach for flexible photothermal icephobic copper mesh with robust superhydrophobicity and active deicing property. Soft Matter 2021, 17, 1901-1911, doi:10.1039/d0sm01930e. [CrossRef] [PubMed]

5. Starostin, A.; Strelnikov, V.; Valtsifer, V.; Lebedeva, I.; Legchenkova, I.; Bormashenko, E. Robust icephobic coating based on the spiky fluorinated $\mathrm{Al}_{2} \mathrm{O}_{3}$ particles. Sci. Rep. 2021, 11, 5394, doi:10.1038/s41598-021-84283-w. [CrossRef] [PubMed]

6. Li, M.; Joung, D.; Hughes, B.; Waldman, S.D.; Kozinski, J.A.; Hwang, D.K. Wrinkling Non-Spherical Particles and Its Application in Cell Attachment Promotion. Sci. Rep. 2016, 6, 30463, doi:10.1038/srep30463. [CrossRef] [PubMed]

7. Visaveliya, N.; Köhler, J. M. Microfluidic Assisted Synthesis of Multipurpose Polymer Nanoassembly Particles for Fluorescence, LSPR, and SERS Activities. Small 2015, 11, 6435-6443, doi:10.1002/smL1.201502364. [CrossRef]

8. Klupp, Taylor, R.N.; Bao, H.; Tian, C.; Vasylyev, S.; Peukert, W. Facile Route to Morphologically Tailored Silver Patches on Colloidal Particles. Langmuir 2010, 26, 13564-13571, doi:10.1021/la102284w. [CrossRef] [PubMed]

9. Yin, J.; Han, X.; Cao, Y.; Lu, C. Surface Wrinkling on Polydimethylsiloxane Microspheres via Wet Surface Chemical Oxidation. Sci. Rep. 2014, 4, 5710, doi:10.1038/srep05710. [CrossRef]

10. Zhao, T.; Qiu, D. One-Pot Synthesis of Highly Folded Microparticles by Suspension Polymerization. Langmuir 2011, 27, 12771-12774, doi:10.1021/la2028912. [CrossRef]

11. Liu, J.; Liu, Y.; Xue, Y.; Ren, Y.; Fan, X.; Wang, R.; Zhang, H.; Zhang, B.; Zhang, Q. Fabrication and characterization of controllable wrinkled-surface polymer microparticles. J. Mater. Sci. 2019, 54, 5852-5864, doi:10.1007/s10853-018-2421-2. [CrossRef]

12. Chew, N.Y.K.; Chan, H.-K. Use of Solid Corrugated Particles to Enhance Powder Aerosol Performance. Pharm. Res. 2001, 18, 1570-1577, doi:10.1023/A:1013082531394. [CrossRef]

13. Cao, G.; Chen, X.; Li, C.; Ji, A.; Cao, Z. Self-Assembled Triangular and Labyrinth Buckling Patterns of Thin Films on Spherical Substrates. Phys. Rev. Lett. 2008, 100, 036102, doi:10.1103/PhysRevLett.100.036102. [CrossRef]

14. Hano, N.; Takafuji, M.; Ihara, H. One-pot preparation of polymer microspheres having wrinkled hard surfaces through selfassembly of silica nanoparticles. Chem. Commun. 2017, 53, 9147-9150, doi:10.1039/c7cc05132h. [CrossRef] [PubMed]

15. Tan, W.K.; Araki, Y.; Yokoi, A.; Kawamura, G.; Matsuda, A.; Muto, H. Micro- and Nano-assembly of Composite Particles by Electrostatic Adsorption. Nanoscale Res. Lett. 2019, 14, 1-9, doi:10.1186/s11671-019-3129-1. [CrossRef]

16. Marschelke, C; Diring, O.; Synytska, A. Reconfigurable assembly of charged polymer- modified Janus and non-Janus particles: from half- raspberries to colloidal clusters and chains. Nanoscale Adv. 2019, 1, 3715-3726, doi:10.1039/c9na00522f. [CrossRef]

17. Nakanishi, T.; Shen, Y.; Wang, J.; Li, H.; Fernandes, P.; Yoshida, K.; Yagai, S.; Takeuchi, M.; Ariga, K.; Kurth, D.G.; et al. Superstructures and superhydrophobic property in hierarchical organized architectures of fullerenes bearing long alkyl tails. J. Mater. Chem. 2010, 20, 1253-1260, doi:10.1039/B916612B. [CrossRef]

18. Thiruvengadathan, R.; Korampally, V.; Ghosh, A.; Ch, A.N.; Gangopadhyay, K.; Gangopadhyay, S. Nanomaterial processing using self-assembly-bottom-up chemical and biological approaches. Rep. Prog. Phys. 2013, 76, 066501, doi:10.1088/00344885/76/6/066501. [CrossRef]

19. Lunn, D.J.; Finnegan, JR Manners, I. Self-assembly of "patchy" nanoparticles: a versatile approach to functional hierarchical materials. Chem. Sci. 2015, 6, 3663-3673, doi:10.1039/c5sc01141h. [CrossRef]

20. Wang, Z.; Wang, H.; Cheng, M.; Li, C.; Faller, R.; Sun, S.; Hu, S. Controllable Multigeometry Nanoparticles via Cooperative Assembly of Amphiphilic Diblock Copolymer Blends with Asymmetric Architectures. ACS Nano 2018, 12, 1413-1419, doi:10.1021/acsnano.7b07777. [CrossRef] [PubMed]

21. Moulin, E.; Armao, J.J.; Giuseppone, N. Triarylamine-Based Supramolecular Polymers: Structures, Dynamics, and Functions. Acc. Chem. Res. 2019, 52, 975-983, doi:10.1021/acs.accounts.8b00536. [CrossRef] 
22. Hanisch, A.; Gröschel, A.H.; Förtsch, M.; Drechsler, M.; Jinnai, H.; Ruhl, T.M.; Schacher, F.H.; Müller, A.H. Counterion-Mediated Hierarchical Self-Assembly of an ABC Miktoarm Star Terpolymer. ACS Nano 2013, 7, 4030-4041, doi:10.1021/nn400031u. [CrossRef]

23. Jia, L.; Zhao, G.; Shi, W.; Coombs, N.; Gourevich, I.; Walker, G.C.; Guerin, G.; Manners, I.; Winnik, M.A. A design strategy for the hierarchical fabrication of colloidal hybrid mesostructures. Nat. Commun. 2014, 5, 3882, doi:10.1038/ncomms4882. [CrossRef]

24. Wang, J.; Le-The, H.; Wang, Z.; Li, H.; Jin, M.; van den Berg, A.; Zhou, G.; Segerink, L.I.; Shui, L.; Eijkel, J.C. Microfluidics Assisted Fabrication of Three- Tier Hierarchical Microparticles for Constructing Bioinspired Surfaces. ACS Nano 2019, 13, 3638-3648, doi:10.1021/acsnano.9b00245. [CrossRef] [PubMed]

25. Liu, W.; Kappl, M.; Butt, H.-J. Tuning the Porosity of Supraparticles. ACS Nano 2019, 13, 13949-13956. [CrossRef] [PubMed]

26. Yang, Q.; Miao, X.; Loos, K. Fabrication of Nano-Sized Hybrid Janus Particles from Strawberry-Like Hierarchical Composites. Macromol. Chem. Phys. 2018, 219, 1800267, doi:10.1002/macp.201800267. [CrossRef]

27. Fairbanks, B.D.; Schwartz, M. P.; Bowman, C.N.; Anseth, K.S. Photoinitiated polymerization of PEG-diacrylate with lithium phenyl-2,4,6-trimethylbenzoylphosphinate: polymerization rate and cytocompatibility. Biomaterials 2009, 30, 6702-6707, doi:10.1016/j.biomaterials.2009.08.055. [CrossRef]

28. Koehler, J.M.; Moeller, F.; Schneider, S.; Guenther, P.M.; Albrecht, A.; Gross, G.A. Size-tuning of monodisperse PMMA nanoparticles by micro-continuous-flow polymerization using a silicon micro-nozzle array. Chem. Eng. J. 2011, 167, 688-693, doi:10.1016/j.cej.2010.09.079. [CrossRef]

29. Serra, C.A.; Khan, I.U.; Chang, Z.; Bouquey, M. Engineering Polymer Microparticles by Droplet Microfluidics. J. Flow Chem. 2013, 3, 66-75, doi:10.1556/JFC-D-13-00014. [CrossRef] [PubMed]

30. Serra, C.A.; Chang, Z. Microfluidic-Assisted Synthesis of Polymer Particles. Chem. Eng. Technol. 2008, 31, 1099-1115, doi:10.1002/ceat.200800219. [CrossRef]

31. Köhler, J.M.; Kraus, I.; Faerber, J.; Serra, C. Continuous-flow preparation of nanoporous metal/polymer composite particles by in situ synthesis of silver nanoparticles in photopolymerized acrylate/diethylene glycol droplets. J. Mater. Sci. 2013, 48, 2158-2166, doi:10.1007/s10853-012-6991-0. [CrossRef]

32. Kronfeld, K.-P.; Ellinger, T Köhler, J.M. Microfluidically prepared sensor particles for determination of chloride by fluorescence quenching of matrix-embedded lucigenin. SN Appl. Sci. 2020, 2, 366-373, doi:10.1007/s42452-020-2155-z. [CrossRef]

33. Visaveliya, N.; Köhler, J.M. Role of Self-Polarization in a Single-Step Controlled Synthesis of Linear and Branched Polymer Nanoparticles. Macromol. Chem. Phys. 2015, 216, 1212-1219, doi:10.1002/macp.201500091 [CrossRef]

34. Visaveliya, N.; Köhler, J.M. Control of Shape and Size of Polymer Nanoparticles Aggregates in a Single-Step Microcontinuous Flow Process: A Case of Flower and Spherical Shapes. Langmuir 2014, 30, 12180-12189, doi:10.1021/la502896s. [CrossRef]

35. Kim, O.H.; Lee, K.; Kim, K.; Lee, B.H.; Choe, S. Optimum conditions for preparing micron-sized PMMA beads in the dispersion polymerization using PVA. Colloid Polym. Sci. 2006, 284, 909-915, doi:10.1007/s00396-006-1464-0. [CrossRef]

36. Shim, S.E.; Kim, K.; Oh, S.; Choe, S. Preparation of Ultra Fine Poly(methyl methacrylate) Microspheres in Methanol-enriched Aqueous Medium. Macromol. Res. 2004, 12, 240-245, https://www.cheric.org/PDF/MMR/MR12/MR12-2-0240.pdf. [CrossRef] [PubMed]

37. Seo, M.; Nie, Z.; Xu, S.; Mok, M.; Lewis, P.C.; Graham, R.; Kumacheva, E. Continuous Microfluidic Reactors for Polymer Particles. Langmuir 2005, 21, 11614-11622, doi:10.1021/la050519e. [CrossRef]

38. Hait, S.K.; Moulik, S.P. Determination of Critical Micelle Concentration (CMC) of Nonionic Surfactants by Donor-Acceptor Interaction with Iodine and Correlation of CMC with Hydrophile-Lipophile Balance and Other Parameters of the Surfactants. J. Surfactants Deterg. 2001, 4, 303-309, https://link.springer.com/article/10.1007/s11743-001-0184-2. [CrossRef]

39. Peltonen, L.; Hirvonen, J.; Yliruusi, J. The Behavior of Sorbitan Surfactants at the Water-Oil Interface: Straight-Chained Hydrocarbons from Pentane to Dodecane as an Oil Phase. J. Colloid Interface Sci. 2001, 240, 272-276, doi:10.1006/jcis.2001.7612. [CrossRef] 